\title{
Inhibition of the BER Factor APE1 Disrupts Repair of Double-Strand DNA Damage in Cells Treated with Low Dose-Rate, but Not High Dose-Rate X- Radiation
}

\section{Anthony Gerald McCluskey ${ }^{*}$ and Marie Boyd}

Experimental Targeted Radiation Therapeutics group, Strathclyde Institute of Pharmacy and Biomedical Sciences, University of Strathclyde, 161 Cathedral Street, Glasgow, G4 ORE, UK

*Corresponding author: Anthony Gerald McCluskey, Experimental Targeted Radiation Therapeutics group, Strathclyde University, 161 Cathedral Street, Glasgow G4 ORE, Uk, Tel: +44 (0) 141548 4738; Fax: +44 (0) 141552 2562; E-mail: anthony.mccluskey@strath.ac.uk

Received date: Sep 18, 2015, Accepted date: Nov 28, 2015, Publication date: Nov 30, 2015

Copyright: (c) 2015 McCluskey AG, et al. This is an open-access article distributed under the terms of the Creative Commons Attribution License; which permits unrestricted use; distribution; and reproduction in any medium; provided the original author and source are credited.

\begin{abstract}
Introduction: Radiotherapy is utilised in the treatment of many cancers, but its efficacy is limited by normal tissue toxicity and new radiotherapy techniques are thus urgently sought. The AP endonuclease APE1 is involved in repair of single strand DNA damage through the break excision repair (BER) pathway and altered levels of APE1 have been found in some cancers. In this study, we investigated the effects of APE1 inhibition, using the APE1-specific inhibitor CRT0044876 (CRT), in tumour cells following exposure to either high dose-rate (HDR) or low dose-rate (LDR) X-irradiation.
\end{abstract}

Materials and Methods: Treatment efficacy was assessed by clonogenic assay followed by isobologram analysis to assess potential synergy. Cell cycle distribution was assessed by propidium iodide staining followed by flow cytometry. Induction of DNA damage and repair was assessed by single cell gel electrophoresis and by $\mathrm{H} 2 \mathrm{~A} . \mathrm{X}$ phosphorylation.

Results: In isobologram analysis of clonogenic assays, combinations of CRT and both HDR and LDR Xirradiation resulted in supra-additive levels of cytotoxicity. Cell cycle analysis showed that, while CRT had no effect on cell cycle distribution, HDR or LDR X-irradiation, and CRT-HDR or CRT-LDR combination treatment induced significant $\mathrm{G}_{2} / \mathrm{M}$ arrest. However, CRT-HDR combinations induced significantly less $\mathrm{G}_{2} / \mathrm{M}$ accumulation than $\mathrm{HDR}$ alone. Analysis of DNA damage indicated that treatment with HDR or LDR X-irradiation and CRT-HDR and CRTLDR combinations induced significant double-strand DNA damage. Cells treated with CRT-HDR exhibited a significant reduction in $\mathrm{YH} 2 \mathrm{~A} . \mathrm{X}$ foci $24 \mathrm{~h}$ after treatment compared to $1 \mathrm{~h}$, suggesting induction of DNA repair mechanisms. However, in cells treated with CRT-LDR, there was no significant difference between H2A.X phosphorylation at $24 \mathrm{~h}$ compared to $1 \mathrm{~h}$, suggesting disruption of dsDNA repair pathways.

Conclusions: Pharmacological inhibition of APE1 enhances the cytotoxicity of high dose-rate and low dose-rate X-irradiation by different mechanisms.

Keywords: BER inhibition; Dose-rate dependent X-irradiation

\section{Introduction}

After surgery, radiotherapy is the most commonly used form of cancer treatment, and it is estimated that $50 \%$ of all patients will require radiotherapy at some stage in their treatment regimen [1]. While the use of external beam radiation (XBR), using a gamma ray or $\mathrm{X}$-ray source is the most commonly used form of radiotherapy, internal radiation sources, either in the form of brachytherapy or targeted radionuclide therapy (TRT) are also routinely utilised for a variety of different diseases [2]. However, while the use of different forms of radiotherapy has proven to be very beneficial to a large number of patients, the differences in the biological responses elicited by different types of radiation treatment are less well understood. The mechanisms by which different types of radiation energies and particles interact with living matter are complex. Factors such as dose, dose-rate, production of reactive oxygen species (ROS) and linear energy transfer (LET) [3,4] can evoke a myriad of different cellular responses to the delivered radiation and can, therefore, influence the overall efficacy of the treatment. Furthermore, in the case of TRT, uptake and retention of the targeting agent, size of the tumour mass and path length of radioisotope decay are also important considerations.

Previously, we reported that cells exposed to XBR and TRT in vitro exhibited different types of direct and radiation-induced biological bystander effects $[5,6]$, thus demonstrating that exposure to different forms of radiation can result in different cellular responses. However, given that the responses elicited by any two types of radiation decay are multifactorial, attempting to investigate the specific differences between various radiation exposures is problematic. One approach, which could help resolve this difficulty, would involve investigating the effects of exposure to a single type of radiation while changing one single parameter in order to elucidate differences in the resultant cellular response to that single change. 
In the case of XBR, one parameter which can easily be altered is the dose-rate of the radiation. Therefore, in this preliminary study, we investigated the response of human glioma cells to $\mathrm{X}$-irradiation, delivered at different dose-rates, in order to gain a better understanding of differences in cellular response.

Exposure of cells to ionizing radiation can result in the formation of various types of DNA lesions, such as single-strand DNA and doublestrand DNA breaks (SSB and DSB respectively) and oxidative base damage. While DSB formation is believed to be the lesion which is primarily responsible for cellular radiotoxicity [2], the majority of the damage which is induced by radiation is in the form of clustered damaged bases [7].

Delivery of radiation at a low dose-rate (LDR), such as that elicited by radioisotopes used in TRT and brachytherapy, results in an increased frequency of sub-lethal DNA damage. This is due to the low frequency of ionisation events, leading to SSB damage which cells are able to repair efficiently before a second ionisation event can occur and convert the SSB into a potentially lethal DSB [8]. Therefore, inhibition of SSB repair mechanisms could increase the longevity of LDR radiation-induced SSBs, thus increasing the likelihood of a second ionisation event leading to increased, potentially lethal, DNA damage.

The BER pathway is responsible for the removal and repair of damaged DNA bases. Previously, we reported that the efficacy of targeted radionuclides was enhanced by inhibition of PARP-1, a protein central to the BER pathway [9]. In this study, we investigated the interaction of XBR with another protein involved in the BER response, namely the AP endonuclease 1 (APE-1) [10].

Following irradiation, damaged bases are removed by DNA glycosylases, resulting in the formation of an apurinic/apyrimidinic (AP) site. APE-1 is a 3-phosphodiesterase which initiates repair of AP sites by inducing nicks in the phosphodiester backbone of the damaged DNA strand upstream of the AP site, thus creating 3'-hydroxyl and 5'deoxyribose phosphate groups flanking the gap [11]. APE-1 is associated with nearly all AP site excision activity and therefore plays a crucial role in the BER pathway [12]. Furthermore, evidence suggests that APE-1 plays distinct roles in the repair of DNA damage by high LET, compared to its activity following low LET radiation-induced DNA damage [13]. We therefore chose to investigate the effects of pharmacological inhibition of APE-1 in combination with XBR delivered at different dose-rates.

\section{Material and Methods}

\section{Cells and culture conditions}

The human glioma cell line UVW was used in this study [14]. Cells were maintained in Minimum Essential Medium containing 10\% foetal calf serum, supplemented with $100 \mathrm{U} / \mathrm{ml}$ penicillin/streptomycin, 2 $\mu \mathrm{g} / \mathrm{ml}$ fungizone and $2 \mathrm{mM}$ glutamine and were cultured at $37^{\circ} \mathrm{C}$ in a $5 \% \mathrm{CO}_{2}$ atmosphere. All media and supplements were purchased from Invitrogen (Paisley, UK).

\section{Treatments}

UVW cells were treated with 0-4 Gy external beam radiation (XBR), delivered using a X-Rad $225 \mathrm{X}$-irradiation cabinet (Precision Xray Inc., Connecticut USA). High dose-rate (HDR) treatments were carried out at a dose-rate of $2.2 \mathrm{~Gy} / \mathrm{min}$ and low dose-rate (LDR) treatments at a dose-rate of $0.22 \mathrm{~Gy} / \mathrm{min}$. Following XBR exposure, cells were incubated at $37^{\circ} \mathrm{C}$ in $5 \% \mathrm{CO}_{2}$ until cells were processed for each experimental procedure, as described below.

The APE-1 inhibitor CRT0044876 (CRT) was purchased from Sigma-Aldrich (Poole, UK) and dissolved in DMSO (Sigma Aldrich). UVW cells were treated with $0-200 \mu \mathrm{M}$ CRT for 24 hours at $37^{\circ} \mathrm{C}$ in $5 \% \mathrm{CO}_{2}$ before assessment. In the case of combination treatments, cells were incubated with CRT for 1 hour prior to XBR exposure.

\section{Clonogenic assay}

Cells were treated with CRT alone, or in combination with low dose-rate or high dose-rate XBR as described above. Thereafter, clonogenic survival was determined as previously described [15].

\section{Synergy analysis}

The efficacy of combinations of CRT and either high or low doserate XBR was examined according to the isobologram method of Steel and Peckham [16-18]. Briefly, from the results of clonogenic assays, dose-effect curves were plotted. From these curves, the doses of CRT and XBR which induced $20 \%$ toxicity (the $\mathrm{IC}_{20}$ isoeffect points) as single agents and in combination were determined and plotted graphically. A line was drawn between the $\mathrm{XBR} \mathrm{IC}_{20}$ isoeffect point on the $y$-axis and the $\mathrm{CRT}_{\mathrm{IC}_{20}}$ isoeffect point on the $\mathrm{x}$-axis, denoting the theoretical alignment of each agent, which would give rise to an additive effect. Combination isoffect points which plotted below this line were therefore suggestive of supra-additive interactions, whereas any isoffect points which plotted directly onto, or above this line were suggestive of additive or infra-additive interactions respectively.

\section{Assessment of Cell Cycle Progression by FACS Analysis}

Cells were seeded in $25 \mathrm{~cm}^{2}$ flasks and exposed to single drug and multi-drug combinations as described above. In order to directly compare the effects on cell cycle progression to the results of clonogenic assay, the same drug concentrations and incubation times were used. Cultures were then detatched by the addition of trypsin, counted using a haemocytometer, washed twice with PBS and resuspended in PBS at a concentration of $1 \times 10^{6}$ cells $/ \mathrm{ml}$. Cells were fixed by addition of $75 \%(\mathrm{v} / \mathrm{v})$ ethanol for $1 \mathrm{~h}$ at $4^{\circ} \mathrm{C}$. Fixed cells were washed twice with PBS and resuspended in $1 \mathrm{ml}$ PBS containing 50 $\mathrm{mg} / \mathrm{ml}$ propidium iodide (Sigma chemicals, Dorset UK) and $5 \mu \mathrm{g} / \mathrm{ml}$ RNase A (Qiagen Ltd. W. Sussex, UK). Cells were stained for $3 \mathrm{~h}$ at $4^{\circ} \mathrm{C}$ before flow cytometry, using a FACSCanto analyser (BD Biosystems, Oxford, UK). Data were analysed using BD FACSDiva ${ }^{\mathrm{TM}}$ software, version 6.1.3.

\section{Single cell gel electrophoresis}

The influence of CRT on the repair of XBR-induced DNA damage was assessed by single cell gel electrophoresis (SCGE) [19-21]. Briefly, DNA fragmentation was determined using the Trevigen CometAssayTM Single Cell Electrophoresis Assay kit (Trevigen Inc., Gaithersburg, Maryland, USA), according to the manufacturer's instructions. DNA was stained with $1 \mathrm{x}$ SYBR-Green solution (Trevigen Inc.) and examined by fluorescence microscopy (435-500 
Citation: McCluskey AG, Boyd M (2015) Inhibition of the BER Factor APE1 Disrupts Repair of Double-Strand DNA Damage in Cells Treated with

nm) using a Zeiss Axiovert inverted microscope (Carl Zeiss Ltd, Welwyn Garden City, Hertfordshire, UK).

Images were captured by a Zeiss MC 100 SPOT camera, and saved by Axiovision 3.0.6.1 software. 100 cells per treatment were analysed using ImageJ software, version 1.44p (NIH, USA) [22]. The amount of DNA fragmentation was expressed as the tail moment, which combined a measurement of the length of the DNA migration with the relative amount of DNA therein [20,21]. The amount of DNA damage in treated UVW cells were assessed 1 hour and 24 hours after XBR.

\section{Assessment of Double-strand DNA Breaks (DSBs) by H2A.X Phosphorylation}

Phosphorylation of histone H2A.X at serine $139(\gamma \mathrm{H} 2 \mathrm{~A} . \mathrm{X})$ was assessed using the H2A.X Phosphorylation Assay Kit (Millipore, Herts. UK). Briefly, cells were seeded and drug-treated, as described above. 1 $\mathrm{h}$ and $24 \mathrm{~h}$ after treatment, cells were trypsinised, counted, washed twice with PBS and fixed by addition of formaldehyde/methanol for 20 $\min$ at $4^{\circ} \mathrm{C}$. Cells were then washed three times with PBS and resuspended, at a concentration of $2 \times 10^{6}$ cells $/ \mathrm{ml}$, in permeabilization solution (5\% saponin, $100 \mathrm{mM}$ HEPES pH 7.4, $1.4 \mathrm{M} \mathrm{NaCl}, 25 \mathrm{mM}$ $\mathrm{CaCl}_{2}$ ) containing anti-phospho-histone H2A.X (Ser139)-FITC conjugate for $20 \mathrm{~min}$ at $4^{\circ} \mathrm{C}$. Fluorescence was measured using a FACSCanto analyser (BD Biosystems, Oxford, UK). Data were analysed using BD FACSDiva ${ }^{\mathrm{TM}}$ software, version 6.1.3.

\section{Statistical analysis}

For clonogenic assays, cell cycle analyses and assessments of $\gamma$ H2A.X levels, the effects of increasing dose of XBR, at both LDR and HDR, alone or in combination with CRT, were assessed by 2-way ANOVA to test for overall differences. Subsequent post-hoc assessments used Bonferroni post-tests, to account for multiple comparisons.

In the case of single cell gel electrophoresis, overall differences between treatment groups was assessed using the non-parametric Kruskal-Wallis test and pair-wise comparisons by post-hoc analysis using Dunn's multiple comparison test. A p value of less than 0.05 was considered statistically significant. All analyses were carried out using GraphPad Prism software, version 4.03 (GraphPad Software Inc).

\section{Results}

\section{Cytotoxic effects of CRT and XBR as single agents}

The cytotoxic effects of CRT and XBR delivered at HDR and LDR were investigated by clonogenic assay and the results are shown in Figure 1. Administration of 50-200 $\mu \mathrm{M}$ CRT induced a modest, but significant dose-dependent reduction in clonogenic survival, compared to untreated cells $(\mathrm{p}<0.05)$. The highest administered dose of CRT (200 $\mu \mathrm{M})$ reduced UVW colony formation to $81 \%$ (Figure $1 \mathrm{~A}$ ).

Likewise, UVW cells exposed to 2 and 4 Gy XBR, delivered at either a high or low dose-rate exhibited a significant dose-dependent decrease in clonogenic survival compared to untreated controls $(\mathrm{p}<0.0001$ and $\mathrm{p}<0.0001$ for HDR and LDR respectively). However, $\mathrm{XBR}$ delivered at a low dose-rate induced significantly less toxicity than XBR delivered at a high dose-rate $(\mathrm{p}<0.0001)$.
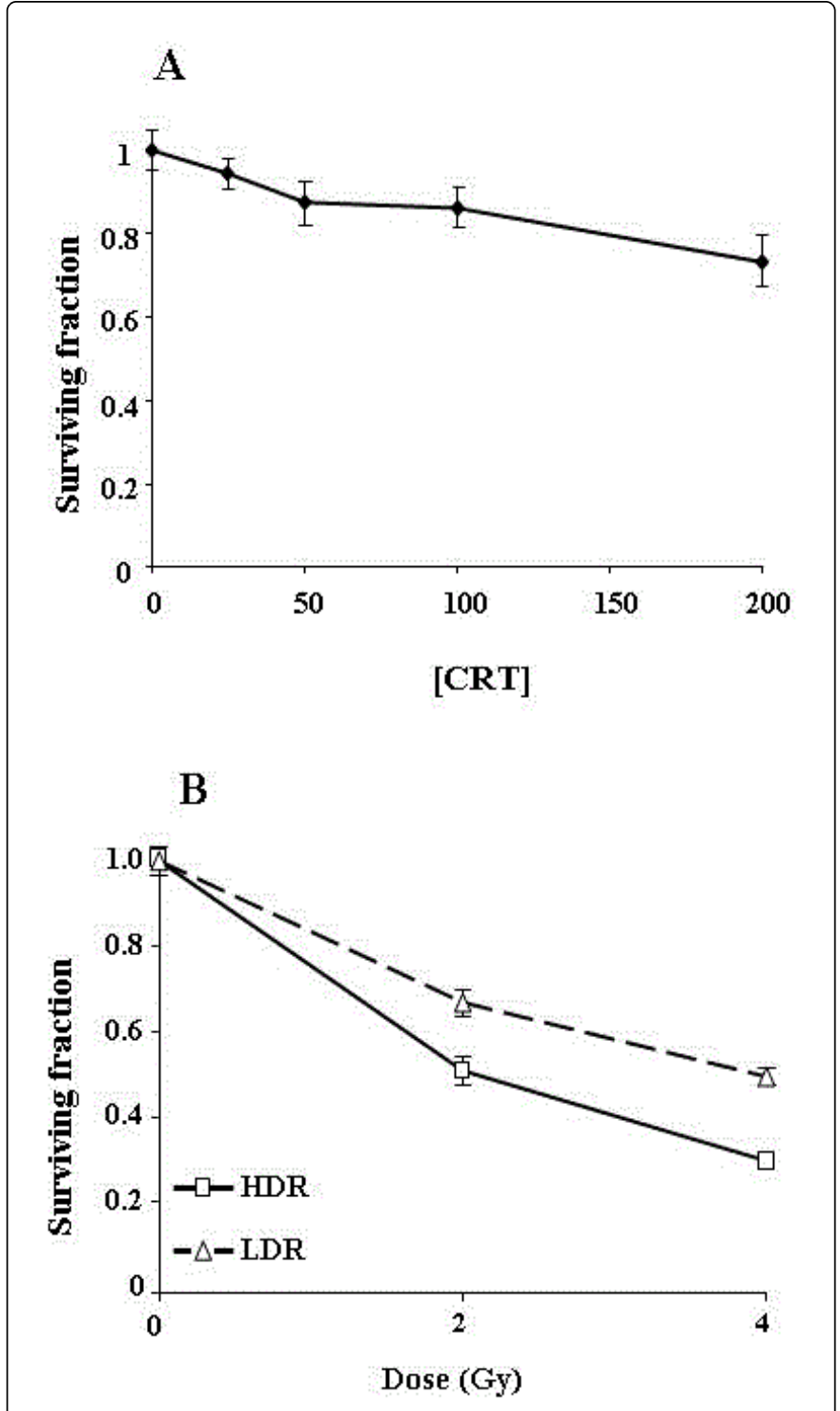

Figure 1: Assessment of the cytotoxic effects of (A) CRT and (B) $\mathrm{XBR}$ at HDR and LDR as single agents. Treatments were assessed by clonogenic assay. The effects of increasing CRT dose were assessed by 1-way ANOVA. The effects of increasing XBR dose and dose-rate were assessed by 2 -way ANOVA.

\section{Cytotoxic effects of CRT and XBR in combination}

The results of treatment with CRT and XBR in combination on the clonogenic survival of UVW cells are shown in Figure 2. Figure 2A shows the results of CRT in combination with HDR X-irradiation and Figure $2 \mathrm{~B}$ shows the results of CRT in combination with LDR XBR. From these survival curves, the doses of CRT and XBR which induced $20 \%$ toxicity (the $\mathrm{IC}_{20}$ isoeffect points) as single agents and in combination were determined. Subsequent isobologram analysis of CRT in combination with high dose-rate and low dose-rate XBR demonstrated that supra-additive interactions were induced by combination doses which caused IC20 levels of toxicity. Dose-rate had no effect on the induction of supra-additivity in UVW cells (Figure 3). 
Citation: McCluskey AG, Boyd M (2015) Inhibition of the BER Factor APE1 Disrupts Repair of Double-Strand DNA Damage in Cells Treated with Low Dose-Rate, but Not High Dose-Rate X-Radiation. J Nucl Med Radiat Ther 6: 269. doi:10.4172/2155-9619.1000269

Page 4 of 7

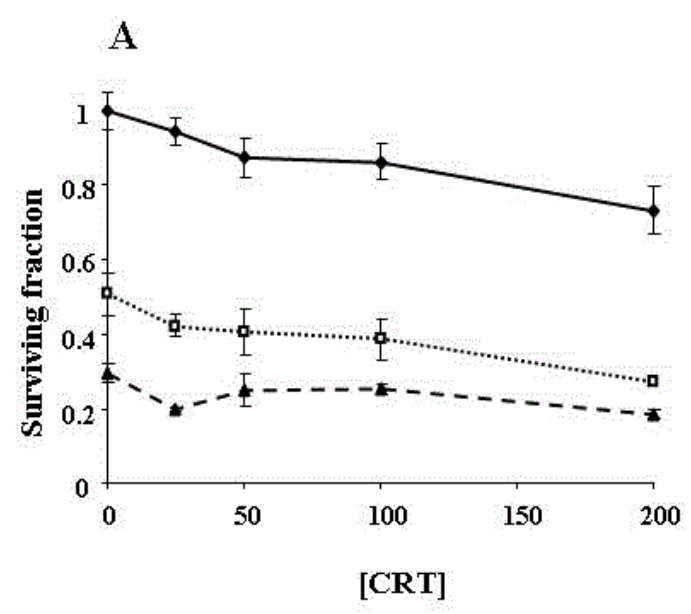

B

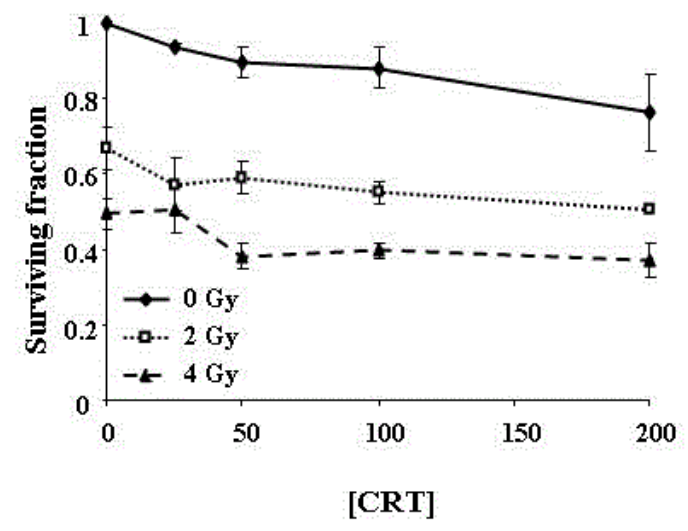

Figure 2: Assessment of the cytotoxic effects of CRT and XBR at (A) HDR and (B) LDR in combination. Treatments were assessed by clonogenic assay.

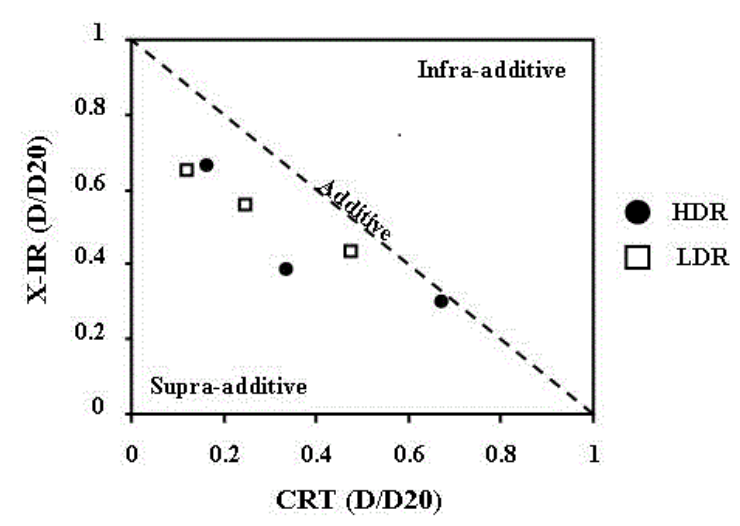

Figure 3: Interaction between CRT and high dose-rate and low dose-rate XBR. The results shown in Figure 2 were assessed by isobologram analysis.

\section{Assessment of Cell Cycle Progression}

The impact of HDR and LDR of radiation and CRT treatment alone and in combination on cell cycle progression were then assessed. Figure 4 shows the distribution of cells in $\mathrm{G}_{2} / \mathrm{M}$ following single agent and combination treatment. Exposure of UVW cells to $100 \mu \mathrm{M}$ CRT induced no change in the cell cycle distribution of UVW cells, compared to untreated controls. In contrast, exposure of UVW cells to 3 Gy XBR, administered at either a high or low dose-rate induced a significant accumulation in cells in $\mathrm{G}_{2} / \mathrm{M} 24 \mathrm{~h}$ after treatment $(\mathrm{p}<0.0001$ and $\mathrm{p}<0.0001$ for HDR and LDR respectively), compared to untreated controls. Likewise, cells treated with $100 \mu \mathrm{M}$ CRT in combination with 3 Gy XBR exhibited significant $G_{2} / M$ arrest, irrespective of the dose-rate of $X$-ray exposure $(p<0.0001$ and $p<0.0001$ for CRT-HDR and CRT-LDR respectively). However, while there was no significant difference in the induction of $\mathrm{G}_{2} / \mathrm{M}$ arrest between LDR single exposure and CRT-LDR combination treatment, CRT-HDR treatment induced significantly less $\mathrm{G}_{2} / \mathrm{M}$ arrest than $\mathrm{HDR}$ alone $(p<0.05)$. With respect to peturbations of other phases of the cell cycle, increases in $G_{2} / M$ arrest were accompanied by concurrent reduction in the proportion of cells in the $G_{1}$ phase. No significant alterations to the number of cells in S-phase were observed (data not shown).

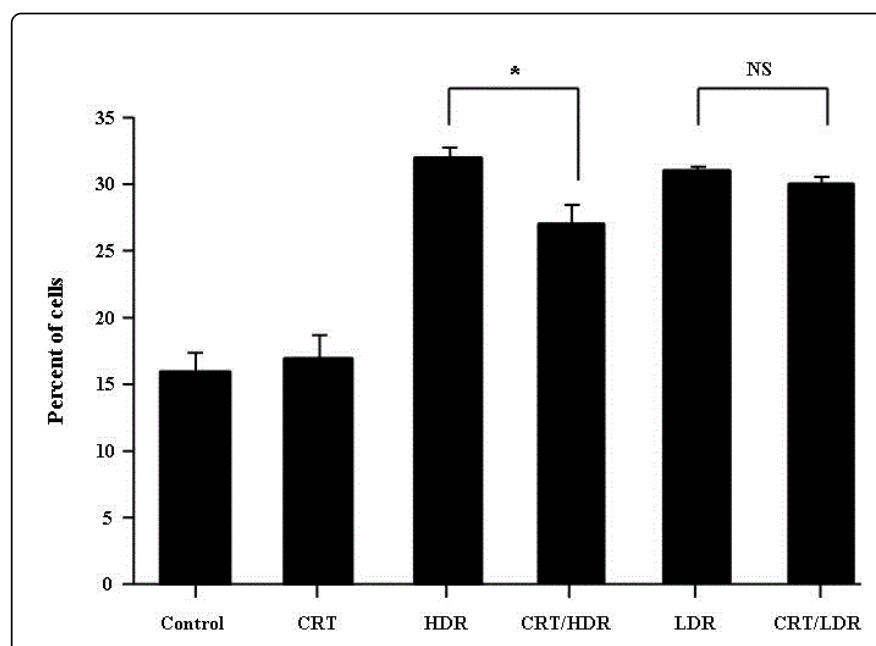

Figure 4: The effects of X-IR and CRT treatment on $G_{2} / M$ accumulation. The effects on UVW cells of CRT and XBR at both dose-rates were assessed by FACS analysis and differences in $G_{2} / M$ accumulation induced by CRT and increasing XBR dose and doserate were assessed by 2-way ANOVA. Results show the mean \pm sem of three separate experiments. Statistical significance: one $\left(^{*}\right)$ and three $\left({ }^{* * *}\right)$ symbols denote $\mathrm{p}<0.05$ and $\mathrm{p}<0.0001$ respectively.

\section{Single cell gel electrophoresis}

Single cell gel electrophoresis was carried out in order to investigate DNA damage following single and combination treatments. The dynamics of DNA repair was assessed by examining DNA damage levels $24 \mathrm{~h}$, compared to $1 \mathrm{~h}$, after treatment (Figure 5).

Analysis of DNA damage by SGCE demonstrated that administration of $100 \mu \mathrm{M}$ CRT had no significant effect on the magnitude of DNA damage in UVW cells at either time point. However, $1 \mathrm{~h}$ after treatment, UVW cells treated with 3 Gy XBR exhibited significant levels of DNA damage, irrespective of the dose- 
rate of exposure $(\mathrm{p}<0.0001$ and $\mathrm{p}<0.05$ for $\mathrm{HDR}$ and $\mathrm{LDR}$ respectively). Likewise, administration of $100 \mu \mathrm{M}$ CRT in combination with 3 Gy XBR also induced significant DNA damage $1 \mathrm{~h}$ after treatment, irrespective of the dose-rate used $(p<0.0001$ and $p<0.0001$ for CRT-HDR and CRT-LDR respectively).

In contrast, $24 \mathrm{~h}$ after treatment, while cells treated with HDR, CRTHDR and CRT-LDR still exhibited significant levels of DNA damage $(\mathrm{p}<0.05, \mathrm{p}<0.0001$ and $\mathrm{p}<0.0001$ for HDR, CRT-HDR and CRT-LDR respectively), the levels of DNA damage in cells treated with XBR at a low dose-rate were not significantly different to untreated controls (Figure 6).

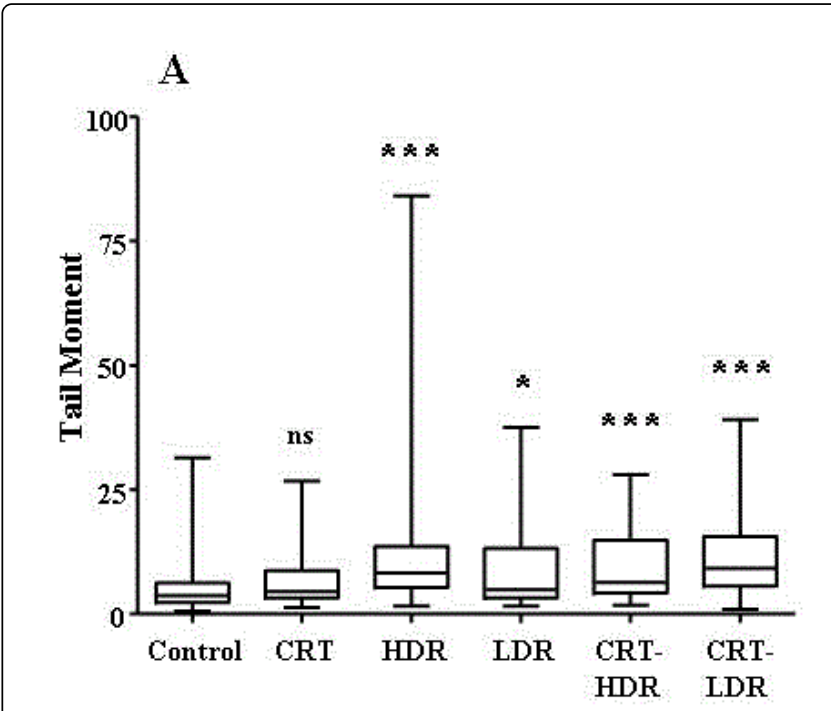

B

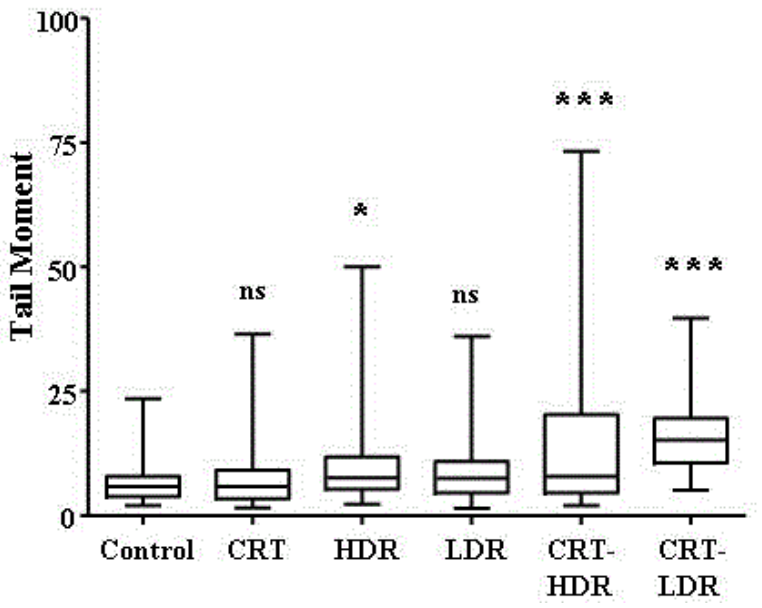

Figure 5: Assessment of DNA damage at (A) $1 \mathrm{~h}$ and (B) $24 \mathrm{~h}$ by single cell gel electrophoresis. 100 cells were assayed per treatment. For each treatment, boxplots represent the $25^{\text {th }}$ percentile, median and $75^{\text {th }}$ percentile. Whisker bars show the minimum and maximum values observed. Statistical significance: one $\left({ }^{*}\right)$ and three $\left({ }^{* *}\right)$ symbols denote $\mathrm{p}<0.05$ and $\mathrm{p}<0.0001$ respectively.

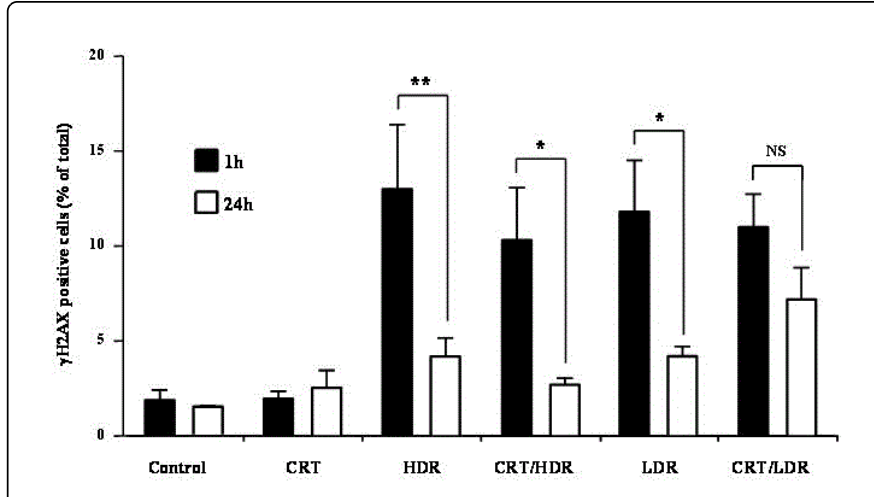

Figure 6: The effects of CRT and XBR treatment on dsDNA damage and repair were assessed by $\gamma \mathrm{H} 2 . \mathrm{AX}$ analysis. Results were analysed by were assessed by 2-way ANOVA and show the mean \pm sem of three separate experiments. Statistical significance: one $\left(^{*}\right)$ and two $\left({ }^{* *}\right)$ symbols denote $\mathrm{p}<0.05$ and $\mathrm{p}<0.001$ respectively.

\section{Assessment of Double-strand DNA Breaks (DSBs) by H2A.X Phosphorylation}

DNA damage and repair was assessed further by investigation of the induction of DSBs by H2A.X phosphorylation. Analysis of $\gamma \mathrm{H} 2 \mathrm{~A}$.X foci in each treatment group by one-way ANOVA demonstrated that $\mathrm{XBR}$ and combination treatments induced significant increases in $\gamma$ H2A.X foci $1 \mathrm{~h}$ after treatment $(\mathrm{p}<0.001)$. When UVW cells were incubated for $24 \mathrm{~h}$ after treatment, significantly reduced levels of $\gamma \mathrm{H} 2 \mathrm{~A}$.X foci compared to $1 \mathrm{~h}$ after treatment were observed, following exposure to HDR, LDR and CRT-HDR, $(\mathrm{p}<0.001, \mathrm{p}<0.05$ and $\mathrm{p}<0.05$ for HDR, LDR and CRT-HDR respectively). However, there was no significant difference in H2A.X phosphorylation observed in UVW cells treated with CRT in combination with low dose-rate XBR at this later time point. This suggests that UVW cells exposed to CRT and low dose-rate XBR exhibited a reduced capacity to resolve $\gamma \mathrm{H} 2 \mathrm{~A}$.X foci.

\section{Discussion}

We have previously demonstrated that cells exposed to XBR and TRT in vitro exhibited diverse and distinct biological responses upon exposure to different types of radiation insult [5,6]. However, attempting to gain a clearer understanding of the different, specific, cellular consequences that are induced by exposure to distinct radiations has proven challenging, due to the wide variety of factors that are affected by different types of radioactive decay. In order to try and resolve this issue, we investigated the effects of changing one, single parameter that can influence the intracellular effects induced by radiation treatment, namely the dose-rate of exposure. We also wished to investigate the effects of concurrent inhibition of the BER pathway, which we have previously shown to enhance the efficacy of targeted radionuclides in vitro [9].

The results of clonogenic assays demonstrated that exposure to 2 and $4 \mathrm{~Gy}$ external beam X-ray radiation (XBR) at a low dose-rate $(0.22$ Gy/min) was significantly less cytotoxic than exposure to the same doses of XBR at a high dose-rate $(2.2 \mathrm{~Gy} / \mathrm{min})(\mathrm{p}<0.0001$, Figure 1$)$. Treatment with 5-200 $\mu \mathrm{M}$ CRT induced a modest, but significant dosedependent reduction in clonogenic survival $(\mathrm{p}<0.05)$. The results of combinations of XBR with the APE-1 inhibitor CRT0044876 (CRT) 
demonstrated that supra-additive cell kill elicited by the combination of XBR and this pharmacological inhibitor of BER were not affected by the dose-rate of XBR exposure (Figures 2 and 3).

Cells exposed to radiation often exhibit disruption to cell cycle progression in vitro and accumulation in the $\mathrm{G}_{2}$-phase is commonly observed [23].The results of our study demonstrate that treatment with 3 Gy XBR at either dose-rate, either alone or in combination with 100 $\mu \mathrm{M}$ CRT, induced significant accumulation of cells in $\mathrm{G}_{2} / \mathrm{M}$, as measured by FACS analysis $(\mathrm{p}<0.0001, \mathrm{p}<0.0001, \mathrm{p}<0.0001$ and $\mathrm{p}<0.0001$ for HDR and LDR, CRT-HDR and CRT-LDR respectively). Cells exposed to CRT as a single agent exhibited no disruption of cell cycle progression.

However, while cells exposed to combination treatment involving low dose-rate XBR exhibited no significant difference in $G_{2} / M$ accumulation compared to LDR alone, the percentage of cells in $\mathrm{G}_{2} / \mathrm{M}$ following CRT-HDR treatment was significantly lower than HDR alone. This suggests that there was a significant subpopulation of UVW cells that were unable to arrest in $\mathrm{G}_{2} / \mathrm{M}$ following exposure to high dose-rate XBR insults when APE-1 was inhibited. However, this effect was not observed in cells exposed to combinations involving low doserate XBR, suggesting that abrogation of cell cycle checkpoints was unaffected by CRT-LDR combinations. This observation demonstrates a difference in the cellular response to high dose-rate and low doserate $\mathrm{XBR}$. The $\mathrm{G}_{2} / \mathrm{M}$ checkpoint is important for limiting radiationinduced toxicity, as it prevents cells with DNA damage from entering mitosis, thus providing an opportunity for DNA repair, or induction of apoptosis and preventing the proliferation of damaged cells [23]. Therefore, the presence of a subpopulation of cells which lack this checkpoint upon exposure to CRT-HDR combinations would increase the likelihood of mitotic catastrophe [24,25] and/or long-term genomic instability [26], both of which can result in increased cytotoxicity and could thus explain the supra-additive cytotoxicity observed in isobologram analysis of CRT-HDR combinations. Previous studies have found that APE-1 interacts with the 9-1-1 complex, a mediator of DNA-damage induced $\mathrm{G}_{2}$ arrest [27-29], thus suggesting a link between BER factors and the $G_{2}$ checkpoint. Therefore, it is possible that this pathway is activated at a higher level in cells exposed to high dose-rate XBR, compared to low dose-rate $\mathrm{XBR}$ and is therefore more susceptible to disruption by inhibition of APE-1. Future studies will investigate the induction of the BER pathway following HDR and LDR X-irradiation, in order to interrogate this hypothesis.

The results of our cell cycle analysis suggest a possible explanation for the supra-additive interaction of CRT with high dose-rate XBR, but they give no insight into the cellular response to low dose-rate XBR. However, the analysis of DNA damage and repair also highlighted differences in the effects of HDR and LDR irradiation, and provide a possible explanation for this latter phenomenon. Assessment of DNA damage by SCGE, which measures single-strand DNA and doublestrand DNA breaks (SSB and DSB respectively) demonstrated that, whereas exposure to high dose-rate XBR resulted in significant DNA damage $1 \mathrm{~h}$ and $24 \mathrm{~h}$ after treatment, cells exposed to low dose-rate XBR exhibited significant DNA damage only at $1 \mathrm{~h}$ after treatment, but not at $24 \mathrm{~h}$. This suggests that the combined SSBs and DSBs elicited by low dose-rate XBR were more rapidly reparable than the lesions induced by high dose-rate XBR. The levels of DNA damage $24 \mathrm{~h}$ after $\mathrm{XBR}$ exposure in combination with CRT remained significantly high irrespective of dose-rate $(\mathrm{p}<0.0001$ and $\mathrm{p}<0.0001$ for CRT-HDR and CRT-LDR respectively), suggesting that inhibition of APE-1 induced a retardation of the cellular repair of low dose-rate XBR-induced DNA damage.

Double-strand DNA breaks are considered to be the most important DNA lesion with respect to induction of cell death [2]. Therefore, we decided to investigate the formation and resolution of H2A.X phosphorylation, which occurs as a consequence of DSB damage [30]. Our studies demonstrated that significant resolution of $\gamma \mathrm{H} 2 \mathrm{~A} . \mathrm{X}$ foci occurred $24 \mathrm{~h}$ after treatment, compared to the levels observed at $1 \mathrm{~h}$, following treatment with high dose-rate and low dose-rate XBR and with high dose-rate in combination with CRT. However, cells exposed to low dose-rate XBR in combination with CRT exhibited no significant reduction in $\gamma \mathrm{H} 2 \mathrm{~A}$.X foci at $24 \mathrm{~h}$ compared to $1 \mathrm{~h}$. This suggests that DSBs induced by low dose-rate XBR are more difficult for cells to resolve than the DSB lesions induced by high dose-rate XBR. Induction of BER following SSB formation and base damage is well established [31], however its role in the DSB response pathway is less well characterised. Interestingly, it has been previously reported that APE-1 inhibition resulted in an accumulation of DSB damage, possibly via the accumulation of unresolved AP sites, leading to replication fork blockage [32]. This may provide a potential mechanism to explain the supra-additive cytotoxicity induced by CRT-LDR combinations. It is possible that exposure to low dose-rate XBR results in complex DSB lesions which are difficult for the cells to repair efficiently. This could, theoretically, lead to a greater involvement of BER machinery in the DNA repair process. In contrast the DSBs induced by high dose-rate XBR may be more easily and more rapidly repaired, and may not require activation of the BER pathway. In this scenario, cells exposed to low dose-rate XBR would be more susceptible to inhibition of APE-1, which would reduce the efficiency of DNA repair and, consequently, increase the likelihood of cell death.

\section{Conclusions}

Our results demonstrated that X-ray exposure, in combination with APE-1 inhibition, resulted in supra-additive cytotxicity, irrespective of the dose-rate utilised. However, the results of cell cycle and DNA damage analysis suggested that different radiation response mechanisms were responsible for synergistic interactions in HDR and LDR-treated cells. APE-1 inhibition in combination with high doserate XBR induced its toxic effects via abrogation of $G_{2}$ arrest, whereas the effects of APE-1 inhibition in combination with low dose-rate XBR were associated with reduced resolution of the DSB repair processes.

These preliminary results highlight differences in cellular response to distinct radiation insults. Research will continue, in order to gain a greater insight into the pathways involved in radiation-induced cell death, with the ultimate aim of improving the efficacy of distinct types of radiation therapy.

\section{References}

1. Porter A, Aref A, Chodounsky Z, Elzawawy A, Manatrakul N, et al. (1999) A global strategy for radiotherapy: a WHO consultation. Clin Oncol (R Coll Radiol) 11: 368-370.

2. Baskar R, Lee KA, Yeo R, Yeoh KW (2012) Cancer and radiation therapy: current advances and future directions. Int J Med Sci 9: 193-199.

3. Hall EJ, Giaccia AJ (2006) Linear energy transfer and relative biological effectiveness. (edn) Radiobiology for the radiologist. Lippincott, Williams \& Wilkins Philadelphia, USA: 106-117.

4. Hall EJ, Giaccia AJ (2006) Repair of radiation damage and the dose-rate effect. Radiobiology for the Radiologist, Lippincott, Williams \& Wilkins Philadelphia, USA, 6: 60-84 
Citation: McCluskey AG, Boyd M (2015) Inhibition of the BER Factor APE1 Disrupts Repair of Double-Strand DNA Damage in Cells Treated with Low Dose-Rate, but Not High Dose-Rate X-Radiation. J Nucl Med Radiat Ther 6: 269. doi:10.4172/2155-9619.1000269

Page 7 of 7

5. Boyd M, Sorensen A, McCluskey AG, Mairs RJ (2008) Radiation qualitydependent bystander effects elicited by targeted radionuclides. J Pharm Pharmacol 60: 951-958.

6. Mairs RJ, Fullerton NE, Zalutsky MR, Boyd M (2007) Targeted radiotherapy: microgray doses and the bystander effect. Dose Response 5: 204-213.

7. Brenner DJ, Ward JF (1992) Constraints on energy deposition and target size of multiply damaged sites associated with DNA double-strand breaks. International journal of radiation biology 61: 737-748.

8. Devlin PM (2007) Radiobiologic Concepts for Bracytherapy. Bracytherapy: Applications and Techniques. Lippincott, Williams \& Wilkins Philadelphia, USA: 1-21.

9. McCluskey AG, Boyd M, Mairs RJ, Tesson M, Pimlott SL, et al. (2012) Inhibition of poly (ADP-ribose) polymerase enhances the toxicity of 131 I-metaiodobenzylguanidine/topotecan combination therapy to cells and xenografts that express the noradrenaline transporter. The Journal of Nuclear Medicine 53: 1146-1154.

10. Thakur S, Sarkar B, Cholia R, Gautam N, Dhiman M, et al. (2014) APE1/ Ref-1 as an emerging therapeutic target for various human diseases: phytochemical modulation of its functions. Experimental And Molecular Medicine 46: e106.

11. Evans AR, Limp-Foster M, Kelley MR (2000) Going APE over ref-1. Mutat Res 461: 83-108.

12. Fritz G, Grösch S, Tomicic M, Kaina B (2003) APE/Ref-1 and the mammalian response to genotoxic stress. Toxicology 193: 67-78.

13. Wang H, Wang X, Chen G, Zhang X, Tang X, et al. (2014) Distinct roles of Apel protein, an enzyme involved in DNA repair, in high or low linear energy transfer ionizing radiation-induced cell killing. J Biol Chem 289: 30635-30644.

14. Boyd M, Mairs RJ, Keith WN, Ross SC, Welsh P, et al. (2004) An efficient targeted radiotherapy/gene therapy strategy utilising human telomerase promoters and radioastatine and harnessing radiation-mediated bystander effects. J Gene Med 6: 937-947.

15. Boyd M, Cunningham SH, Brown MM, Mairs RJ, Wheldon TE (1999) Noradrenaline transporter gene transfer for radiation cell kill by 131I meta-iodobenzylguanidine. Gene Ther 6: 1147-1152.

16. Berenbaum MC (1989) What is synergy? Pharmacol Rev 41: 93-141.

17. Greco WR, Bravo G, Parsons JC (1995) The search for synergy: a critical review from a response surface perspective. Pharmacol Rev 47: 331-385.

18. Steel GG, Peckham MJ (1979) Exploitable mechanisms in combined radiotherapy-chemotherapy: The concept of additivity. Int J Radiat Oncol Biol Phys 5: 85-91.
19. McCluskey AG, Boyd M, Ross SC, Cosimo E, Clark AM, et al. (2005) [131I]meta-iodobenzylguanidine and topotecan combination treatment of tumors expressing the noradrenaline transporter. Clin Cancer Res 11: 7929-7937.

20. Olive PL, Banáth JP, Durand RE (1990) Detection of etoposide resistance by measuring DNA damage in individual Chinese hamster cells. J Natl Cancer Inst 82: 779-783.

21. Olive PL, Banath JP, Durand RE (1990) Heterogeneity in RadiationInduced DNA Damage and Repair in Tumor and Normal Cells Measured Using the "Comet" Assay. Radiat Res 122: 86-94.

22. http://imagej.nih.gov/ij.

23. Stark GR, Taylor WR (2004) Analyzing the G2/M checkpoint. Methods Mol Biol 280: 51-82.

24. Castedo M, Perfettini JL, Roumier T, Andreau K, Medema R, et al. (2004) Cell death by mitotic catastrophe: a molecular definition. Oncogene 23: 2825-2837.

25. Vakifahmetoglu H, Olsson M, Zhivotovsky B (2008) Death through a tragedy: mitotic catastrophe. Cell Death Differ 15: 1153-1162.

26. Suzuki K, Ojima M, Kodama S, Watanabe M (2003) Radiation-induced DNA damage and delayed induced genomic instability. Oncogene 22: 6988-6993.

27. Gembka A, Toueille M, Smirnova E, Poltz R, Ferrari E, et al. (2007) The checkpoint clamp, Rad9-Rad1-Hus1 complex, preferentially stimulates the activity of apurinic/apyrimidinic endonuclease 1 and DNA polymerase beta in long patch base excision repair. Nucleic Acids Res 35: 2596-2608.

28. Parrilla-Castellar ER, Arlander SJ, Karnitz L (2004) Dial 9-1-1 for DNA damage: the Rad9-Hus1-Rad1 (9-1-1) clamp complex. DNA Repair (Amst) 3: 1009-1014.

29. Hwang BJ, Jin J, Gao Y, Shi G, Madabushi A, et al. (2015) SIRT6 protein deacetylase interacts with MYH DNA glycosylase, APE1 endonuclease, and Rad9-Rad1-Hus1 checkpoint clamp. BMC Mol Biol 16: 12.

30. Kuo LJ, Yang LX (2008) Gamma-H2AX - a novel biomarker for DNA double-strand breaks. In Vivo 22: 305-309.

31. Dianov GL, Hübscher U (2013) Mammalian base excision repair: the forgotten archangel. Nucleic Acids Res 41: 3483-3490.

32. Sultana R, Abbotts R, Mohammed MZ, Patel PM, Madhusudan S, et al. (2012) Synthetic lethal targeting of DNA double-strand break repair deficient cells by human apurinic/apyrimidinic endonuclease inhibitors. International journal of cancer 131: 2433-2444. 